\title{
Occupational Exposure to Pesticides and Central Nervous System Tumors: Results from the CERENAT Case-control Study
}

\author{
Isabelle BALDI ( $\square$ isabelle.baldi@u-bordeaux.fr) \\ Universite de Bordeaux https://orcid.org/0000-0003-0738-2673 \\ Lucie De Graaf \\ Universite de Bordeaux \\ Ghislaine Bouvier \\ Universite de Bordeaux \\ Anne Gruber \\ Universite de Bordeaux \\ Hugues Loiseau \\ Centre Hospitalier Universitaire de Bordeaux \\ Matthieu Meryet-Figuiere \\ Centre Francois Baclesse Centre de Lutte Contre le Cancer \\ Sarah Rousseau \\ Centre Hospitalier Universitaire de Bordeaux \\ Pascale Fabbro-Peray \\ Universite de Montpellier \\ Pierre Lebailly \\ Centre Francois Baclesse Centre de Lutte Contre le Cancer
}

\section{Research Article}

Keywords: Central Nervous System tumor, Glioma, Meningioma, Etiology, Pesticides, Agriculture, Green Spaces, Occupational Exposures

DOl: https://doi.org/10.21203/rs.3.rs-278595/v1

License: @ (i) This work is licensed under a Creative Commons Attribution 4.0 International License. Read Full License 


\section{Abstract}

Background: The etiology of the central nervous system (CNS) tumors remains largely unknown. The role of pesticide exposure has been suggested by several epidemiological studies, but with no definitive conclusion. Objective: To analyze associations between occupational pesticide exposure and primary CNS tumors in adults in the CERENAT study.

Methods: CERENAT is a multicenter case-control study conducted in France in 2004-2006. Data about occupational pesticide uses - in and outside agriculture were collected during detailed face-to-face interviews and reviewed by experts for consistency and exposure assignment. Odds ratios (ORs) and $95 \%$ confidence intervals $(95 \% \mathrm{Cl})$ were estimated with conditional logistic regression.

Results: A total of 596 cases (273 gliomas, 218 meningiomas, 105 others) and 1192 age- and sex-matched controls selected in the general population were analyzed. Direct and indirect exposures to pesticides in agriculture were respectively assigned to 125 (7.0\%) and 629 (35.2\%) individuals and exposure outside agriculture to $146(8.2 \%)$ individuals. For overall agricultural exposure, we observed no increase in risk for all brain tumors (OR=1.04, 0.69-1.57) and a slight increase for gliomas $(\mathrm{OR}=1.37,0.79-2.39)$. Risks for gliomas were higher when considering agricultural exposure for more than 10 years $(\mathrm{OR}=2.22,0.94-2.24)$ and significantly trebled in open field agriculture $(\mathrm{OR}=3.58,1.20-0.70)$. Increases in risk were also observed in non-agricultural exposures, especially in green space workers who were directly exposed $(\mathrm{OR}=1.89,0.82-4.39)$, and these were statistically significant for those exposed for over 10 years $(\mathrm{OR}=2.84,1.15$ 6.99).

Discussion: These data support some previous findings regarding the potential role of occupational exposures to pesticides in CNS tumors, both inside and outside agriculture.

\section{Introduction}

Epidemiological knowledge regarding central nervous system (CNS) tumors, including incidence data and etiological research, remains limited. Data from several population-based cancer registries demonstrate that their annual incidence reaches as much as 20/100 000 (Ostrom et al. 2018b; Pouchieu et al. 2018; Wöhrer et al. 2009), when considering all histological subtypes, both malignant and non-malignant. While diagnosis and prognosis of CNS tumors has gradually improved over time, their incidence has been observed to increase in several countries, most notably among the elderly (Miranda-Filho et al. 2017; Philips et al. 2018; Pouchieu et al. 2018). This trend is probably not fully explained by population ageing, changes in case registration or improvement in health access and in diagnosis. In this context, the role of risk factors must be explored (Miranda-Filho 2017). Beside intrinsic factors (gender, ethnic groups, allergic conditions, family and personal history, genetic polymorphisms), some exogenous agents are demonstrated (ionizing radiations) or suspected (pesticides, electromagnetic fields, diet, solvents, hormonal factors) as being risk factors for CNS tumors (Ostrom et al. 2018a; Wrensch et al. 2002). The pesticide hypothesis dates back to the 1980s when excess CNS brain tumor mortality was repeatedly observed in farmers' historical cohorts. Case-control studies and historical cohorts before the 2000s relied on crude exposure parameters such as job titles and their results were non consistent (Cordier et al. 1988; Figà-Talamanca et al. 1993; Fincham et al. 1992; Forastiere et al. 1993; Kross et al. 1996; Morrison et al. 1992; Smith-Rooker et al. 1992), although a study in Northern Italy found a four times higher risk of glioma with exposure to nitrosable fungicides or insecticides (Musicco et al. 1988). More recent studies have used refined pesticide exposure assessment based on detailed questionnaires and/or expertise and analyzed CNS tumor by subtypes. In the Upper Midwest Study, a large case-control study in the USA including 341 brain tumors in women and 457 in men, no increase in risk was observed for glioma with pesticide exposure globally (Ruder et al. 2006; Yiin et al. 2012), in men (Ruder et al. 2004), and only a trend restricted to carbamate insecticide use in women (Carreón et al. 2005). Another case-control study in Nebraska observed an increase in risk only for workers involved in farming for 55 years and over (Lee et al. 2005). Using a job-exposure matrix for pesticide use definition, a third case-control study in the USA evidenced a doubling in the risk of meningioma in women exposed to herbicides, while no association was found between gliomas and pesticide exposure (Samanic et al. 2008). In a case-control study conducted in Southwestern France, an increase in risk was shown among the individuals who were the most exposed to pesticides, especially in vineyards and it was more pronounced for gliomas (Provost et al. 2007). More recently, additional results were obtained from two large prospective agricultural cohorts. The Agricultural Health Study in the USA found a significant fourfold increase in farmers most exposed to chlorpyrifos (Lee et al. 2004) and a threefold increase in their spouses using domestic or occupational organochlorines (Louis et al. 2017). In the French Agrican cohort, elevated risks were observed in farmers exposed to specific crops (peas, beets, potatoes) and risk doubled in those who applied pesticides (Piel et al. 2017). Analysis focused on carbamate insecticides, fungicides and herbicides pointed to some specific active ingredients being associated with a high increase in the risk (Piel et al. 2019a, 2019b).

We present here new results from a multicenter case-control study in France, exploring the relationship between CNS tumors and pesticide occupational exposures, taking into account the CNS subtypes and accurate definitions of pesticide exposures.

\section{Methods Population}

Briefly, the CERENAT case-control study, has been described in detail elsewhere (Coureau et al. 2014): it was conducted in four French administrative areas (Gironde, Calvados, Manche and Hérault) and included i) patients aged 16 and over with a diagnosis of incident benign or malignant CNS (brain and spinal cord) tumor between June 2004 and May 2006, established either by a neuro-pathological assessment or by clinical and radiological assessment for cases with no histological diagnosis and living in one of the four areas when diagnosed, ii) for each case, two controls with no history of CNS tumor, randomly selected from the local electoral rolls during the period 2005-2008, individually matched on age (+/- 2 years), sex and area of residence.

Primary brain tumors with the following ICDO-3 topography codes were included: C70.0-C70.9, C71.0-C71.9 and C72.2-C72.9. Patients with recurrent tumors, metastases, pituitary tumors, genetic syndrome or AIDS were excluded. Cases were grouped by morphology codes as gliomas, meningiomas, and other 
tumors (acoustic neurinomas, lymphomas and other unspecified primary brain tumors).

\section{Data collection}

Data were collected in standardized questionnaires by trained interviewers during face-to-face structured interviews. When patients were in a severe clinical condition or deceased, a proxy was invited to complete a simplified questionnaire. For all participants, socio-demographic characteristics, medical history, lifestyle, environmental data and complete occupational histories with beginning and end dates (including kind of industry, activity and main tasks) were collected.

\section{Pesticide exposure assessment}

Besides job calendars, in-depth life-long questionnaires on pesticide exposures were completed by all subjects who gave a positive answer to one or more of the following 4 screening questions "Have you ever worked on a farm?", "Have you ever applied pesticides on crops?", "Have you ever worked in contact with crops?", "Have you ever used pesticides in non-agricultural jobs?". The specific questionnaires included detailed information on various tasks (beginning and end dates, number of days per year, equipment used) including treatment (mixing, spraying, equipment cleaning) and other tasks (pruning, thinning, bending/tying up, harvesting, etc.). Three experts in pesticide exposure (PFP, PL, IB) reviewed all the job calendars and specific questionnaires independently for consistency and to determine exposure parameters for each individual: direct or indirect exposure in vineyard, open field, fruit and vegetable growing, gardening, wood industry and pest-control. Duration of exposure (in years and in cumulated life-long days) was determined for each type of exposure and the median of the distribution was considered as the threshold for exploring risks in those most exposed.

\section{Analysis}

The index date for each case and his two matched controls was the date of case diagnosis. Pesticide exposure was considered as a binary variable (yes/no) for each exposure parameter, and also according to the median of cumulative exposure defined in controls. Cumulative exposure was defined as the sum of lifetime days of treatment for agricultural exposures and as the duration of jobs (in years) for non-agricultural exposures. Conditional logistic regression for matched sets was used to estimate odds ratios and $95 \%$ confidence intervals. All statistical tests were two-sided and a global test for each categorical indicator was performed. The following variables were considered as potential confounders: level of education (primary school or less, secondary school, high school and university), smoking (in pack-years), alcohol consumption (classified as excessive in men over 21 glasses of wine, cider, beer or spirits per week and over 14 glasses per week in women). None of these variables was retained in the final analysis as alcohol and smoking were not associated with health outcome and level of education was closely correlated to the jobs and exposures under study. Separate analyses were run for each histological type. We used 2-sided statistical tests and a 5\% significance level. Analyses were performed with the SAS ${ }^{\circledR}$ software, version 9.2 (SAS Institute Inc, Cary, NC, United States).

\section{Results}

\section{Population characteristics}

Among the eligible subjects, $95 \%$ of cases and $61 \%$ of controls were reached. A total of $596(73 \%)$ cases and $1,192(45 \%)$ controls were finally included in the CERENAT study. The participation rate was $66 \%$ for glioma cases and $75 \%$ for meningioma cases. The main reasons for non-participation were refusals, severe condition or death without proxy. Non-included cases were older than included cases (mean age: 63 years vs. 58 years).

The cases were 273 patients with gliomas, 218 with meningiomas, and 105 with other brain tumors (68 neurinomas, 12 lymphomas, and 25 undefined or others). The proportion of proxy interviews was $25 \%$ for gliomas, $6 \%$ for meningiomas and $18.5 \%$ for other brain tumors. The average age was 55.4 years for patients with gliomas, 60.2 years for meningiomas and 57.6 for other tumors (Table 1 ). Women represented $42.1 \%, 75.7 \%$ and $53.3 \%$ of the population for each type of tumor respectively. The level of education was higher in controls than in cases whatever the type of tumor. The proportion of alcohol excessive consumers was slightly higher in controls (8.5\%) than in cases (6.2\%). Life-long tobacco smoking concerned half of the population, in a comparable proportion in cases and controls, although the proportion of smokers who exceeding 20 pack-years life-long was slightly higher in cases (41.2\%) than in controls (34.8\%). 
Table 1

Demographic and lifestyle characteristics of cases and controls overall and by histological subtype, CERENAT ( $N=1788)$

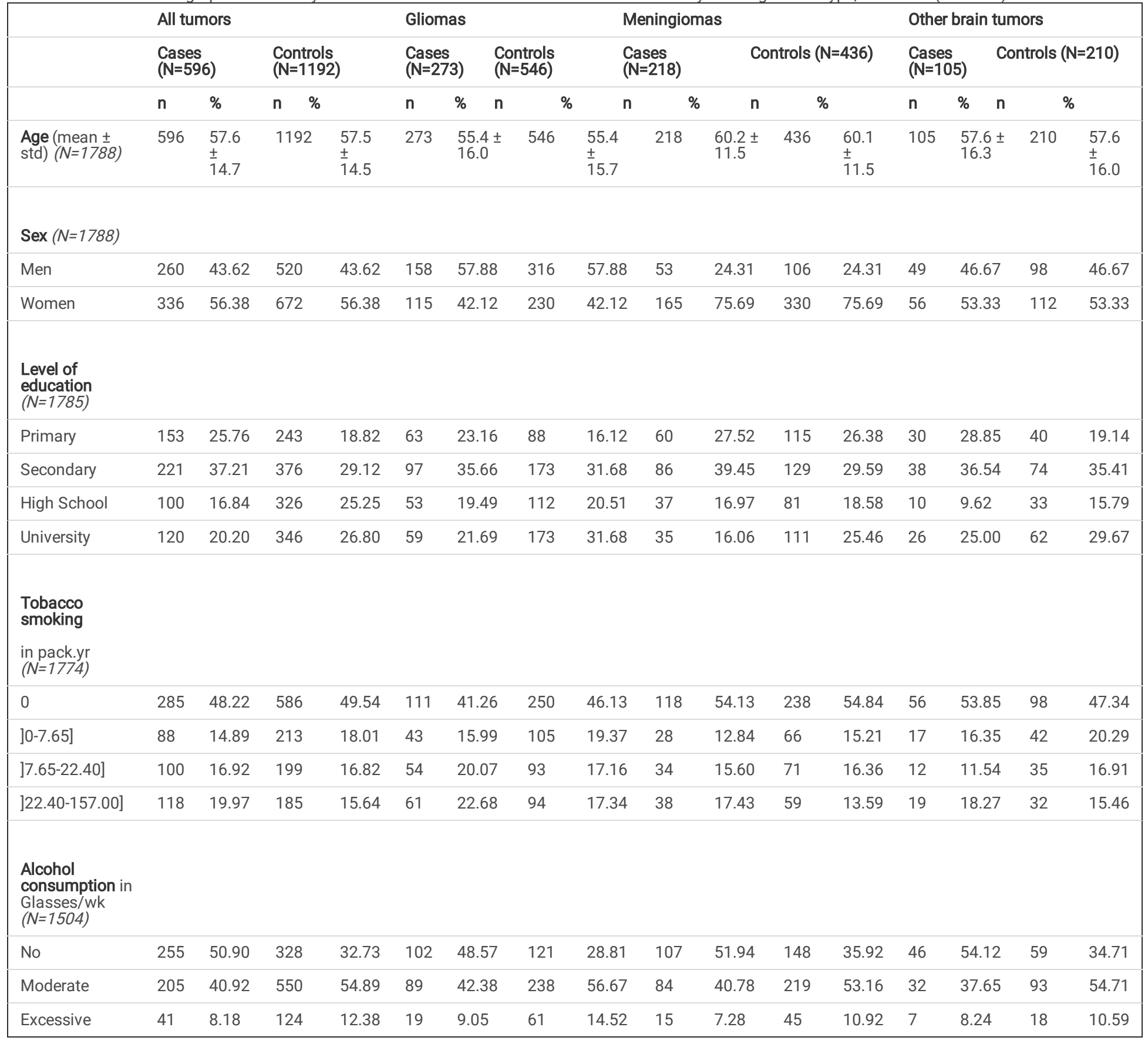

\section{Description of pesticide exposure}

Information on occupational pesticide exposure was available for all subjects, and about $2 \%$ of data on exposure duration were missing. Figure 1 presents the proportion of individuals exposed to pesticides according to the status (all controls, all cases, gliomas, meningiomas) and the type of exposure (direct and indirect in agriculture and outside agriculture).

\section{- Agricultural pesticide exposures}

A total of 754 subjects (42.2\%) were classified as exposed to pesticides in agriculture. One hundred and twenty five individuals (7.0\%) had sprayed pesticides on crops during their occupational life. These direct exposures concerned 65 subjects in vine-growing (3.6\%), 46 in open field (2.6\%) and 39 in fruit or vegetable-growing (2.2\%). The median duration of direct exposure was 15, 21 and 12 years respectively for the three types of crops, corresponding to a median of 114,54 and 55 cumulated days of treatment life-long.

More than a third of the population ( $\mathrm{N}=629,35.2 \%)$ had never sprayed pesticides but had been working in contact with crops for one year or more. The proportions of subjects reporting these indirect exposures were respectively $23.6 \%(\mathrm{~N}=423)$ in vine-growing including harvesting $(\mathrm{N}=351)$ and other re-entry tasks $(\mathrm{N}=72), 12.6 \%$ in open field $(\mathrm{N}=226)$ including hay making $(\mathrm{N}=77)$, cereal harvesting or sowing $(\mathrm{N}=149)$ and $11.7 \%$ in fruit and vegetable growing 
( $N=209)$ for picking and pruning. The median duration of indirect exposure was 5 years in vine-growing ( 5 for harvesting and 12 for other re-entry tasks), 7 years in open field and 8 years for fruit \& vegetable growing.

\section{- Non-agricultural pesticide exposures}

One hundred and forty-six subjects (8.2\%) were classified as exposed to pesticides in non-agricultural occupations: 36 (2.0\%) in gardening \& landscape (24 of them exposed in treatment tasks and 12 through indirect exposures), 90 (5.0\%) in the wood industry (20 directly and 70 indirectly exposed), and 21 ( $1.2 \%$ ) in insect control for public health (15 directly and 6 indirectly exposed). The medians of the duration of exposure were 10 years in gardening, 14 years in wood industry and 15 years in pest control.

\section{Risks associated with agricultural exposures}

Associations between agricultural exposures and CNS tumors are presented in Table 2. Direct agricultural exposure was not significantly associated with an increase in risk for all brain tumors together and all types of exposures $(\mathrm{OR}=1.04,0.69-1.57)$ but a slightly positive trend was observed when restricting the analysis to gliomas $(\mathrm{OR}=1.37,0.79-2.39)$, while a decrease in risk was observed in meningiomas $(\mathrm{OR}=0.79,0.36-1.76)$ and other tumors $(\mathrm{OR}=0.65,0.23-1.87)$ (Table 3). In the most exposed farmers (life-long number of days of treatment over the median), the risk of brain tumors overall was increased (OR=1.58, 0.83 3.01) and the risk of glioma was doubled $(\mathrm{OR}=2.22,0.94-5.24)$. 
Table 2

Association between agricultural pesticide exposures and brain tumors, overall and by subtypes, CERENAT ( $N=1$

Gliomas

All tumors

\section{Cases Controls $(\mathrm{N}=596)$}

\section{Cases}

$(\mathrm{N}=273)$

Meningiomas

$\mathrm{n}$

\section{Agriculture overall}

$(N=1788)$

\begin{tabular}{|c|c|c|c|c|c|c|c|c|c|c|c|c|c|c|c|c|c|c|}
\hline No & 374 & & 660 & & 1.00 & & 167 & & 295 & & 1.00 & & 147 & & 247 & & 1.00 & \\
\hline Indirect & 176 & 29.5 & 453 & 38.0 & $0.68^{\star 1}$ & $\begin{array}{l}0.54- \\
0.84\end{array}$ & 77 & 28.2 & 212 & 38.8 & $0.64^{\star 1}$ & $\begin{array}{l}0.46- \\
0.88\end{array}$ & 61 & 28.0 & 168 & 38.5 & $0.58^{\star 1}$ & $\begin{array}{l}0 . \\
0\end{array}$ \\
\hline Direct & 46 & 7.7 & 79 & 6.6 & 1.04 & $\begin{array}{l}0.69- \\
1.57\end{array}$ & 29 & 10.6 & 39 & 7.1 & 1.37 & $\begin{array}{l}0.79- \\
2.39\end{array}$ & 10 & 4.6 & 21 & 4.8 & 0.79 & $\begin{array}{l}0 . \\
1 .\end{array}$ \\
\hline $\begin{array}{l}\text { Direct>86 } \\
\text { days }^{\star 2}\end{array}$ & 20 & 4.0 & 27 & 2.7 & 1.58 & $\begin{array}{l}0.83- \\
3.01\end{array}$ & 13 & 6.2 & 14 & 3.5 & 2.22 & $\begin{array}{l}0.94- \\
5.24\end{array}$ & 4 & 2.0 & 7 & 1.7 & 1.22 & $\begin{array}{l}0 . \\
4 .\end{array}$ \\
\hline
\end{tabular}

\section{Vinegrowing}

\begin{tabular}{|c|c|c|c|c|c|c|c|c|c|c|c|c|c|c|c|c|c|c|}
\hline No & 457 & & 843 & & 1.00 & & 209 & & 377 & & 1.00 & & 168 & & 309 & & 1.00 & \\
\hline $\begin{array}{l}\text { Indirect } \\
\text { /Reentry }\end{array}$ & 23 & 3.9 & 49 & 4.1 & 0.83 & $\begin{array}{l}0.49- \\
1.40\end{array}$ & 10 & 3.7 & 18 & 3.3 & 1.02 & $\begin{array}{l}0.44- \\
2.33\end{array}$ & 9 & 4.1 & 25 & 5.7 & 0.62 & 0 \\
\hline $\begin{array}{l}\text { Indirect } \\
\text { /Harvesting }\end{array}$ & 93 & 15.6 & 258 & 21.6 & $0.62^{\star 1}$ & $\begin{array}{l}0.46- \\
0.82\end{array}$ & 40 & 14.6 & 131 & 24.0 & $0.50^{\star 1}$ & $\begin{array}{l}0.32- \\
0.76\end{array}$ & 37 & 17.0 & 87 & 20.0 & 0.73 & 0. \\
\hline Direct & 23 & 3.9 & 42 & 3.5 & 1.05 & $\begin{array}{l}0.54- \\
1.64\end{array}$ & 14 & 5.1 & 20 & 3.7 & 1.21 & $\begin{array}{l}0.56- \\
2.61\end{array}$ & 4 & 1.8 & 15 & 3.4 & 0.47 & 0 \\
\hline $\begin{array}{l}\text { Direct }>114 \\
\text { days }{ }^{\star 2}\end{array}$ & 10 & 2.0 & 17 & 1.7 & 1.16 & $\begin{array}{l}0.49- \\
2.72\end{array}$ & 7 & 3.3 & 9 & 2.1 & 1.68 & $\begin{array}{l}0.54- \\
5.23\end{array}$ & 1 & 0.5 & 5 & 1.2 & 0.36 & 0 \\
\hline
\end{tabular}

\section{Open field farming}

$(N=1788)$

\begin{tabular}{|c|c|c|c|c|c|c|c|c|c|c|c|c|c|c|c|c|c|c|}
\hline No & 517 & & 999 & & 1.00 & & 234 & & 461 & & 1.00 & & 198 & & 367 & & 1.00 & \\
\hline $\begin{array}{l}\text { Indirect } \\
\text { (Harvest) }\end{array}$ & 19 & 3.2 & 58 & 4.9 & 0.62 & $\begin{array}{l}0.36- \\
1.07\end{array}$ & 6 & 2.2 & 26 & 4.8 & 0.46 & $\begin{array}{l}0.18- \\
1.15\end{array}$ & 6 & 2.8 & 24 & 5.5 & 0.45 & $\begin{array}{l}0 . \\
1 .\end{array}$ \\
\hline $\begin{array}{l}\text { Indirect } \\
\text { (Reentry) }\end{array}$ & 39 & 6.5 & 110 & 9.2 & 0.69 & $\begin{array}{l}0.47- \\
1.01\end{array}$ & 20 & 7.3 & 47 & 8.6 & 0.83 & $\begin{array}{l}0.48- \\
1.44\end{array}$ & 9 & 4.1 & 42 & 9.6 & $0.42^{\star 1}$ & $\begin{array}{l}0 . \\
0 .\end{array}$ \\
\hline Direct & 21 & 3.5 & 25 & 2.1 & 1.63 & $\begin{array}{l}0.88- \\
3.04\end{array}$ & 13 & 4.8 & 12 & 2.2 & 2.00 & $\begin{array}{l}0.91- \\
4.41\end{array}$ & 5 & 2.3 & 3 & 0.7 & 2.59 & $\begin{array}{l}0 . \\
1 i\end{array}$ \\
\hline $\begin{array}{l}\text { Direct }>54 \\
\text { days }^{\star \star \star 2}\end{array}$ & 10 & 2.0 & 7 & 0.7 & $3.58^{\star 1}$ & $\begin{array}{l}1.20- \\
10.70\end{array}$ & 6 & 2.9 & 4 & 1.0 & 3.02 & $\begin{array}{l}0.84- \\
10.79\end{array}$ & 3 & 1.5 & 0 & 0.0 & - & - \\
\hline
\end{tabular}

\section{Fruit/vegetable growing}

$(N=1788)$

\begin{tabular}{|c|c|c|c|c|c|c|c|c|c|c|c|c|c|c|c|c|c|c|}
\hline No & 513 & & 1027 & & 1.00 & & 233 & & 466 & & 1.00 & & 192 & & 385 & & 1.00 & \\
\hline Indirect & 70 & 11.7 & 139 & 11.7 & 1.01 & $\begin{array}{l}0.74- \\
1.38\end{array}$ & 30 & 11.0 & 66 & 12.1 & 0.91 & $\begin{array}{l}0.56- \\
1.45\end{array}$ & 23 & 10.6 & 46 & 10.6 & 1.00 & $\begin{array}{l}0 \\
1\end{array}$ \\
\hline Direct & 13 & 2.2 & 26 & 2.2 & 1.00 & $\begin{array}{l}0.51- \\
1.97\end{array}$ & 10 & 3.7 & 14 & 2.6 & 1.43 & $\begin{array}{l}0.62- \\
3.30\end{array}$ & 3 & 1.4 & 5 & 1.1 & 1.20 & $\begin{array}{l}0 \\
5\end{array}$ \\
\hline $\begin{array}{l}\text { Direct>55 } \\
\text { days }^{* 2}\end{array}$ & 4 & 0.8 & 6 & 0.6 & 1.33 & $\begin{array}{l}0.37- \\
4.70\end{array}$ & 3 & 1.4 & 2 & 0.5 & 2.99 & $\begin{array}{l}0.50- \\
17.89\end{array}$ & 1 & 0.5 & 1 & 0.2 & 1.96 & $\begin{array}{l}0 \\
3\end{array}$ \\
\hline
\end{tabular}

${ }^{* 1} p<0.05,{ }^{* 2}$ median of the distribution of duration values (in number of days life-long) 
Considering the crops separately, only slight increases were observed for direct exposure when considering all tumors together and regardless of exposure level in vine-growing $(\mathrm{OR}=1.05,0.54-1.64)$ and in open field $(\mathrm{OR}=1.63,0.88-3.04)$, and no increase was seen in fruit/vegetable growing. Risks increased in the most exposed (life-long cumulative days over the median) and became significant in open field (OR=3.58, 1.20-10.70). This increase was explained by an increase in the risk of gliomas in the most exposed $(\mathrm{OR}=1.68,0.54-5.23$ in vine-growing, $\mathrm{OR}=3.02,0.84-10.79$ in open field, $\mathrm{OR}=2.99,0.50-17.89$ in vegetable and fruit-growing).

For indirect exposures, a decrease in risk was observed for all tumors (OR=0.68, 0.54-0.84) and for gliomas and meningiomas separately. This decrease remained when considering re-entry tasks that can happen during the treatment season and harvesting separately.

\section{Risks associated with non-agricultural pesticide exposures}

Associations between non-agricultural exposures and CNS tumors are presented in Table 3. In green spaces, where 16 cases and 20 controls were exposed, overall risk of brain tumors tended to increase in subjects directly exposed to pesticides (OR=1.89, 0.82-4.39), and to a lesser extent in indirectly exposed subjects $(\mathrm{OR}=1.43,0.45-4.50)$. The risk was more than doubled and significant for subjects with the longest exposures (over 10 years) $(\mathrm{OR}=2.84,1.15-6.99)$. Increases in risk were found in analysis restricted to gliomas (direct exposure: $O R=2.19,0.58-8.6$ ) while numbers were too limited for conclusions in meningioma (5 cases and 1 control). 
Table 3

Association between non-agricultural pesticide exposures and CNS tumors, overall and by subtypes, CERENAT ( $N=178 \varepsilon$

Gliomas

Meningiomas

All tumors

\begin{tabular}{|c|c|c|c|c|c|c|c|c|c|c|c|c|c|c|c|c|}
\hline $\begin{array}{l}\text { Cases } \\
(\mathrm{N}=596)\end{array}$ & $\begin{array}{l}\text { Controls } \\
(\mathrm{N}=1192)\end{array}$ & & & & & & & & & & & & & & & $\begin{array}{l}\text { Case } \\
(\mathrm{N}=1\end{array}$ \\
\hline \% & $\% \mathrm{E}$ & OR & Cl95\% & $n$ & $\begin{array}{l}\% \\
\mathrm{E}\end{array}$ & $n$ & $\% \mathrm{E}$ & OR & Cl95\% & $n$ & $\begin{array}{l}\% \\
\mathrm{E}\end{array}$ & $n$ & $\% \mathrm{E}$ & OR & $\mathrm{Cl} 95 \%$ & $\mathrm{n}$ \\
\hline
\end{tabular}

\section{Outside Agriculture}

$(N=1788)$

\begin{tabular}{|c|c|c|c|c|c|c|c|c|c|c|c|c|c|c|c|c|c|c|c|}
\hline No & 541 & & 1107 & & 1.00 & & 247 & & 506 & & 1.00 & & 202 & & 410 & & 1.00 & & 92 \\
\hline Indirect & 31 & 5.2 & 52 & 4.4 & 1.24 & $\begin{array}{l}0.78- \\
1.97\end{array}$ & 15 & 5.5 & 23 & 4.2 & 1.33 & $\begin{array}{l}0.69- \\
2.56\end{array}$ & 10 & 4.6 & 18 & 4.1 & 1.15 & $\begin{array}{l}0.51- \\
2.58\end{array}$ & 6 \\
\hline Direct & 24 & 4.0 & 33 & 2.8 & 1.50 & $\begin{array}{l}0.88- \\
2.55\end{array}$ & 11 & 4.0 & 17 & 3.1 & 1.34 & $\begin{array}{l}0.62- \\
2.91\end{array}$ & 6 & 2.8 & 8 & 1.8 & 1.52 & $\begin{array}{l}0.53- \\
4.41\end{array}$ & 7 \\
\hline
\end{tabular}

\begin{tabular}{|c|c|c|c|c|c|c|c|c|c|c|c|c|c|c|c|c|c|c|c|}
\hline \multicolumn{20}{|c|}{$\begin{array}{l}\text { Green Spaces } \\
(N=1788)\end{array}$} \\
\hline No & 580 & & 1173 & & 1.00 & & 266 & & 536 & & 1.00 & & 213 & & 435 & & 1.00 & & 101 \\
\hline Indirect & 5 & 0.8 & 7 & 0.6 & 1.43 & $\begin{array}{l}0.45- \\
4.50\end{array}$ & 2 & 0.8 & 5 & 0.9 & 0.80 & $\begin{array}{l}0.16- \\
4.12\end{array}$ & 3 & 1.4 & 1 & 0.2 & 6.00 & $\begin{array}{l}0.62- \\
57.68\end{array}$ & 0 \\
\hline Direct & 11 & 1.8 & 12 & 1.0 & 1.89 & $\begin{array}{l}082- \\
4.39\end{array}$ & 5 & 1.9 & 5 & 0.9 & 2.19 & $\begin{array}{l}0.58- \\
8.36\end{array}$ & 2 & 0.9 & 0 & 0.0 & - & - & 4 \\
\hline $\begin{array}{l}\text { Duration } \\
>10 \text { yrs }\end{array}$ & 12 & 2.0 & 9 & 0.8 & 2.84 & $\begin{array}{l}1.15- \\
6.99 *\end{array}$ & 5 & 1.8 & 5 & 0.9 & 1.98 & $\begin{array}{l}0.57- \\
6.87\end{array}$ & 5 & 2.3 & 0 & 0.0 & - & - & 3 \\
\hline
\end{tabular}

\begin{tabular}{|c|c|c|c|c|c|c|c|c|c|c|c|c|c|c|c|c|c|c|c|}
\hline \multicolumn{20}{|c|}{$\begin{array}{l}\text { Wood industry } \\
(N=1788)\end{array}$} \\
\hline No & 562 & & 1136 & & 1.00 & & 256 & & 521 & & 1.00 & & 208 & & 414 & & 1.00 & & 98 \\
\hline Indirect & 27 & 4.5 & 43 & 3.6 & 1.27 & $\begin{array}{l}0.78- \\
2.08\end{array}$ & 13 & 4.8 & 18 & 3.3 & 1.45 & $\begin{array}{l}0.71- \\
2.96\end{array}$ & 8 & 3.7 & 17 & 3.9 & 0.94 & $\begin{array}{l}0.40- \\
2.20\end{array}$ & 6 \\
\hline Direct & 7 & 1.2 & 13 & 21.1 & 1.09 & $\begin{array}{l}0.44- \\
2.74\end{array}$ & 4 & 1.5 & 7 & 1.3 & 1.16 & $\begin{array}{l}0.34- \\
3.98\end{array}$ & 2 & 0.9 & 5 & 1.1 & 0.80 & $\begin{array}{l}0.15- \\
4.11\end{array}$ & 1 \\
\hline $\begin{array}{l}\text { Duration } \\
>14 \text { yrs }\end{array}$ & 19 & 3.2 & 26 & 2.2 & 1.49 & $\begin{array}{l}0.81- \\
2.74\end{array}$ & 8 & 2.9 & 11 & 2.0 & 1.47 & $\begin{array}{l}0.59- \\
3.65\end{array}$ & 4 & 1.8 & 9 & 2.1 & 0.88 & $\begin{array}{l}0.26- \\
2.98\end{array}$ & 5 \\
\hline
\end{tabular}

\begin{tabular}{|c|c|c|c|c|c|c|c|c|c|c|c|c|c|c|c|c|c|c|c|}
\hline $\begin{array}{l}\text { Pest } \\
\text { control } \\
(N=1788\end{array}$ & & & & & & & & & & & & & & & & & & & \\
\hline No & 587 & & 1180 & & 1.00 & & 270 & & 541 & & 1.00 & & 216 & & 432 & & 1.00 & & 101 \\
\hline Indirect & 2 & 0.3 & 4 & 0.3 & 1.00 & $\begin{array}{l}0.18- \\
5.46\end{array}$ & 1 & 0.4 & 0 & 0.0 & - & - & 0 & 0.0 & 1 & 0.2 & - & - & 1 \\
\hline Direct & 7 & 1.2 & 8 & 0.7 & 1.75 & $\begin{array}{l}0.64- \\
4.83\end{array}$ & 2 & 0.7 & 5 & 0.9 & 0.8 & $\begin{array}{l}0.16- \\
4.12\end{array}$ & 2 & 0.9 & 3 & 0.7 & 1.33 & $\begin{array}{l}0.22- \\
7.98\end{array}$ & 3 \\
\hline $\begin{array}{l}\text { Duration } \\
>15 \text { yrs }\end{array}$ & 0 & 0.0 & 4 & 0.3 & - & - & 0 & 0.0 & 2 & 0.4 & - & - & 0 & 0.0 & 2 & 0.5 & - & - & 2 \\
\hline
\end{tabular}

In the wood industry, where 34 cases and 56 controls were exposed, a slight increase was observed for all CNS tumors, in indirectly (1.27, 0.78-2.08) and directly exposed subjects $(\mathrm{OR}=1.09,0.44-2.74)$, essentially explained by increases in gliomas (indirect exposure $\mathrm{OR}=1.45,0.71-2.96$, direct exposure $\mathrm{OR}=1.16$, $0.34-3.98)$. When restricting the analysis to specific industries, the highest risks were observed in railroad workers in charge of treating wood crossbars $(\mathrm{OR}=2.38,0.72-7.78)$ and in sawmill workers $(\mathrm{OR}=1.90,0.90-4.01)$.

In pest control workers, only 9 cases and 12 controls were exposed and the risk of brain tumor was increased only in directly exposed $(0 \mathrm{R}=1.75,0.64-4.83)$ with too limited numbers for conclusions by subtypes. 


\section{Discussion}

In this case-control study in France, increases in the risk of central nervous system tumors were observed in relation to various occupational pesticide exposures in agriculture but also outside agriculture. In the most exposed individuals, the risk of glioma was non-significantly trebled in open field and in fruitgrowing and multiplied by 1.68 in vine-growing. Elevated risks of glioma were also observed for non-agricultural use of pesticides, especially in workers in green spaces and in the wood industry, and to a lesser extent in pest control workers. No increase in risk was seen for meningioma, nor in indirectly exposed individuals in agriculture. Although the total number of cases included was quite large, most of the elevated risks we found did not reach the statistical significance because of limited numbers when considering tumor subtypes together with specific types of pesticide exposures. Thus, these results can only be interpreted as trends, but they are important to consider because of the strength of some associations that we observed. Moreover, these results were globally consistent, showing higher risks in gliomas and in most exposed individuals for almost all the types of pesticide use.

The main strengths of this study include the enrolment of incident cases supported by population-based cancer registries, face-to-face interviews, the analysis of sub-types of tumors (gliomas, meningiomas), accurate pesticide exposure assessment (exploring agricultural and non-agricultural jobs, direct and indirect exposures). Considering the $73 \%$ participation rate in cases and $45 \%$ in controls, we cannot rule out selection bias. However, the lower participation of subjects with gliomas and elderly people, more frequently exposed to pesticides as shown by observations of participants, is likely to have decreased our risk estimates and biased our results toward the null. Apart from this, we do not see any clear reasons why the participation would be related to pesticide exposures especially as the study was presented to participants as dealing with environmental and occupational factors and CNS health in general, without mentioning the hypothesis on pesticides. Recall bias is a concern in our study as in any retrospective study. However, we believe that this bias was limited by the review of exposure data by experts, who considered job titles as well as responses to specific questionnaires to ensure exposure assessment consistency.

One of the lessons from our study, as already raised by results from a previous study, is the difficulty of highlighting associations when histological types of CNS tumors and kind of exposures are not analyzed separately. This could explain why studies using imprecise metrics for pesticide exposure, such as job titles, have failed to demonstrate an association (Fincham et al. 1992; Forastiere et al. 1993). In our study, the highest risks were observed for gliomas in open field farmers. Wheat and corn were the main crops they had treated in their occupational lives, sometimes in combination with other crops, such as potato, sunflower, rape or beet. Some of them have also raised livestock and may have used insecticides on them. This open field context implies the use of a wide variety and combination of pesticides during a given season and even more life-long, leading to complex toxicological issues. Our result is not in line with those of studies developed in the US in open field farming: associations between pesticide use and risk of brain tumors were unclear in the Upper Midwest Study (Carreón et al. 2005; Ruder et al. 2004) and so far limited to chlorpyrifos in applicators (Lee et al. 2004) and organochlorines (lindane and chlordane) in spouses in the Agricultural Health Study (Louis et al. 2017), while these two studies covered areas (lowa, South Carolina, Michigan, Minnesota, Wisconsin) devoted to open field farming (wheat, corn, beet, etc.). However, American farming differs from French, by larger and more frequently monocultural farms, that may be associated with different practices, work organization and equipment, all factors that can influence pesticide exposures. But our result in open field farming is consistent with those from the French Agrican cohort that found elevated risks for CNS tumors in farmers using pesticides, more pronounced in those growing peas, beets and potatoes (Piel et al. 2017). Even if not significant, we also found elevated risk of gliomas in relation with the longest pesticide exposures in vine-growing, consistent with the historical case-control study by Mussico in Italy (Musicco et al. 1988), with an ecological analysis performed on vine-growing at the national scale in France (Viel et al. 1998), and with a previous case-control study we conducted in the Bordeaux area (Provost et al. 2007). Results on fruit and vegetable growing are less conclusive, but indicated a trend towards an increased risk of glioma in the most exposed, for which no other evidence in the literature has been found. Few studies have explored the association of CNS tumors with pesticide exposures outside agriculture. We observed a significant doubling in risk in green space workers, consistent with a study in golf course workers that found an elevated mortality for CNS tumors compared to the USA general population (Kross et al. 1996). The non-significant doubling of risk that we found in workers exposed in the wood industry is in line with a case-control study on gliomas that showed a raised risk among wood workers, attributed to exposure to organochlorine wood preservative and solvents (Cordier et al. 1988). Our conclusions on pest control workers are limited because of small numbers, but the slight increase in risk we found in the most exposed is in line with a study in Roma that found an excess in CNS tumor mortality in a retrospective cohort of pest control workers (Figà-Talamanca et al. 1993).

In this study, we have not explored the role of specific active ingredients, as people generally cannot remember them life-long. However, the increases in risk we observed across several crops and also outside agriculture, suggest either of the role of a large range of pesticides or of the role of pesticides that have been indicated for multiple uses. Carbamates, that have been pointed out by several studies (Carreón et al. 2005; Navas-Acién et al. 2002; Piel et al. 2019a, 2019a), fulfill the second hypothesis as they have been used as insecticides on crops (including seed treatment) and animals, as well as herbicides and fungicides (mainly dithiocarbamates), but we cannot rule out the possibility that several other molecules, among the more than 1,000 that have been marketed since 1950 , could play a role.

\section{Conclusions}

In conclusion, our study brings new evidence on the association of pesticides and CNS tumors in agriculture: the associations were statistically significant in open field workers, but trends were also observed in vine-growing and fruit growing, especially for gliomas and for the most exposed workers. Even newer evidence are the associations we found outside agriculture, with almost a trebling in risk among green spaces workers exposed for more than 10 years. These results have implications for enhancing preventive measures in agriculture but also for paying particular attention to pesticide exposures outside agriculture.

\section{Declarations ACKNOWLEDGEMENTS}


The authors thank JM. Constans, O. Coskun, S. Eimer and A. Vital for their radiological or pathological expertise, C.Auguin, G. Blaizot, AS. Lacauve, L. Molinari, E. Niez, X. Schwall and S. Schwall for interviewing the subjects, A. Jaffré, V. Loyant, N. Bousquet, E. Berteaud and C. Dantas for their helpful collaboration in the study, and all the clinicians who helped us to contact the patients. The study was supported by grants from the Fondation de France, the Agence Française de Sécurité Sanitaire de l'Environnement et du Travail, the Association pour la Recherche contre le Cancer, the Ligue contre le Cancer, the Institut National de la Santé Et de la Recherche Médicale - ATC Environnement et Santé.

\section{Conflict of Interest}

The authors declare they have no actual or potential competing financial interests.

\section{References}

1. Carreón T, Butler MA, Ruder AM, Waters MA, Davis-King KE, Calvert GM, et al. 2005. Gliomas and Farm Pesticide Exposure in Women: The Upper Midwest Health Study. Environ Health Perspect 113:546-551.

2. Cordier S, Poisson M, Gerin M, Varin J, Conso F, Hemon D. 1988. Gliomas and exposure to wood preservatives. Br J Ind Med 45: $705-709$.

3. Coureau G, Bouvier G, Lebailly P, Fabbro-Peray P, Gruber A, Leffondre K, et al. 2014. Mobile phone use and brain tumours in the CERENAT case-control study. Occup Environ Med 71:514-522.

4. Figà-Talamanca I, Mearelli I, Valente P, Bascherini S. 1993. Cancer mortality in a cohort of rural licensed pesticide users in the province of Rome. Int J Epidemiol 22:579-583.

5. Fincham SM, Hanson J, Berkel J. 1992. Patterns and risks of cancer in farmers in Alberta. Cancer 69:1276-1285.

6. Forastiere F, Quercia A, Miceli M, Settimi L, Terenzoni B, Rapiti E, et al. 1993. Cancer among farmers in central Italy. Scand J Work Environ Health 19:382389.

7. Kross BC, Burmeister LF, Ogilvie LK, Fuortes LJ, Fu CM. 1996. Proportionate mortality study of golf course superintendents. Am J Ind Med 29:501-506.

8. Lee WJ, Blair A, Hoppin JA, Lubin JH, Rusiecki JA, Sandler DP, et al. 2004. Cancer incidence among pesticide applicators exposed to chlorpyrifos in the Agricultural Health Study. J Natl Cancer Inst 96:1781-1789.

9. Lee WJ, Colt JS, Heineman EF, McComb R, Weisenburger DD, Lijinsky W, et al. 2005. Agricultural pesticide use and risk of glioma in Nebraska, United States. Occup Environ Med 62:786-792.

10. Louis LM, Lerro CC, Friesen MC, Andreotti G, Koutros S, Sandler DP, et al. 2017. A prospective study of cancer risk among Agricultural Health Study farm spouses associated with personal use of organochlorine insecticides. Environ Health 16:95.

11. Miranda-Filho A, Piñeros M, Soerjomataram I, Deltour I, Bray F. 2017. Cancers of the brain and CNS: global patterns and trends in incidence. Neurooncology 19:270-280.

12. Morrison HI, Wilkins K, Semenciw R, Mao Y, Wigle D. 1992. Herbicides and cancer. J Natl Cancer Inst 84:1866-1874.

13. Musicco M, Sant M, Molinari S, Filippini G, Gatta G, Berrino F. 1988. A case-control study of brain gliomas and occupational exposure to chemical carcinogens: the risk to farmers. Am J Epidemiol 128: 778-785.

14. Navas-Acién A, Pollán M, Gustavsson P, Floderus B, Plato N, Dosemeci M. 2002. Interactive effect of chemical substances and occupational electromagnetic field exposure on the risk of gliomas and meningiomas in Swedish men. Cancer Epidemiol Biomarkers Prev 11: 1678-1683.

15. Ostrom QT, Gittleman H, Stetson L, Virk S, Barnholtz-Sloan JS. 2018a. Epidemiology of Intracranial Gliomas. Prog Neurol Surg 30:1-11.

16. Ostrom QT, Gittleman H, Truitt G, Boscia A, Kruchko C, Barnholtz-Sloan JS. 2018b. CBTRUS Statistical Report: Primary Brain and Other Central Nervous System Tumors Diagnosed in the United States in 2011-2015. Neuro-oncology 20:iv1-iv86.

17. Philips A, Henshaw DL, Lamburn G, O'Carroll MJ. 2018. Brain Tumours: Rise in Glioblastoma Multiforme Incidence in England 1995-2015 Suggests an Adverse Environmental or Lifestyle Factor. J Environ Public Health 2018:7910754.

18. Piel C, Pouchieu C, Carles C, Béziat B, Boulanger M, Bureau M, et al. 2019a. Agricultural exposures to carbamate herbicides and fungicides and central nervous system tumour incidence in the cohort AGRICAN. Environ Int 130:104876.

19. Piel C, Pouchieu C, Migault L, Béziat B, Boulanger M, Bureau M, et al. 2019b. Increased risk of central nervous system tumours with carbamate insecticide use in the prospective cohort AGRICAN. Int J Epidemiol 48:512-526.

20. Piel C, Pouchieu C, Tual S, Migault L, Lemarchand C, Carles C, et al. 2017. Central nervous system tumors and agricultural exposures in the prospective cohort AGRICAN. Int J Cancer 141:1771-1782.

21. Pouchieu C, Gruber A, Berteaud E, Ménégon P, Monteil P, Huchet A, et al. 2018. Increasing incidence of central nervous system (CNS) tumors (2000-2012): findings from a population based registry in Gironde (France). BMC Cancer 18:653.

22. Provost D, Cantagrel A, Lebailly P, Jaffré A, Loyant V, Loiseau H, et al. 2007. Brain tumours and exposure to pesticides: a case-control study in southwestern France. Occup Environ Med 64:509-514.

23. Ruder AM, Waters MA, Butler MA, Carreón T, Calvert GM, Davis-King KE, et al. 2004. Gliomas and farm pesticide exposure in men: the upper midwest health study. Arch Environ Health 59: 650-657.

24. Ruder AM, Waters MA, Carreón T, Butler MA, Davis-King KE, Calvert GM, et al. 2006. The Upper Midwest Health Study: a case-control study of primary intracranial gliomas in farm and rural residents. J Agric Saf Health 12: 255-274. 
25. Samanic CM, De Roos AJ, Stewart PA, Rajaraman P, Waters MA, Inskip PD. 2008. Occupational exposure to pesticides and risk of adult brain tumors. Am J Epidemiol 167:976-985.

26. Smith-Rooker JL, Garrett A, Hodges LC, Shue V. 1992. Prevalence of glioblastoma multiforme subjects with prior herbicide exposure. J Neurosci Nurs 24:260-264.

27. Wöhrer A, Waldhör T, Heinzl H, Hackl M, Feichtinger J, Gruber-Mösenbacher U, et al. 2009. The Austrian Brain Tumour Registry: a cooperative way to establish a population-based brain tumour registry. J Neurooncol 95:401-411.

28. Wrensch M, Minn Y, Chew T, Bondy M, Berger MS. 2002. Epidemiology of primary brain tumors: current concepts and review of the literature. Neurooncology 4: 278-299.

29. Yiin JH, Ruder AM, Stewart PA, Waters MA, Carreón T, Butler MA, et al. 2012. The Upper Midwest Health Study: a case-control study of pesticide applicators and risk of glioma. Environ Health 11:39. 